\title{
Development of In-pipe Inspection Robot
}

\author{
Atul A. Gargade ${ }^{1}$, Dr. Shantipal S. Ohol ${ }^{2}$ \\ ${ }^{I}$ Mechanical Engineering Department, College of Engineering Pune, India \\ ${ }^{2}$ Mechanical Engineering Department, College of Engineering Pune, India
}

\begin{abstract}
An in-pipe inspection robots are designed to remove the labour force and to act in inaccessible environment. In this paper we present a comprehensive study of in-pipe inspection robot. After some period every pipeline requires inspection and maintenance to ensure their safety and integrity. So, in-pipe inspection robots are used to inspect varies pipeline elements such as straight pipelines, elbow and branches internally. Inpipe inspection robot inspect the pipes of various size and find the defects and obstacles in the pipes. There are many in-pipe inspection robots which are differ by their power source, steering mechanism and application. This paper also shows the comparative study of different in-pipe inspection robots. Section 6 shows the new developed steering mechanism for improvising working style of in-pipe inspection robot. Still the applications of in-pipe inspection robots are limited according to pipeline material, pipe size and working environment.
\end{abstract}

Keywords: branches, defects, elbow, in-pipe robot, steering mechanism

\section{Introduction}

Pipeline is the major tool of transportation. Many kinds of pipes are being utilized to construct important lifelines such as water and gas supply in our contemporary society. Also pipes are widely used in chemical industries and in gulf countries for carrying petrol, diesel, oil etc. But recently many troubles are occurring in the pipelines because of natural calamities and mechanical damages from third parties and defects are occurring in the pipelines. If the defects in the pipe are caused by aging, corrosion, rust and nature calamity then it is difficult to find out the defects and the place of the defects, and also there is great amount of loss. Thus scheduled inspection must be done. If we decide to do this inspection manually then large amount of time, effort and labour is necessary to grub up the pipes that are buried in the ground. If the robot can inspect inside the pipes, fast and accurate examination is able to do at low cost.

Recently, many researchers have been studying robotic systems capable of moving freely inside the pipes. There are several types of in-pipe inspection robots which are classified according to their movement patterns, as shown in figure 1. Design of each of this robot is depend upon the specific application.

As shown in figure 1(a), for example, the pig type is one of the most well-known commercial one, which is passively driven by the fluid pressure inside pipelines. It has been employed for the inspection of pipelines with large diameters [2].

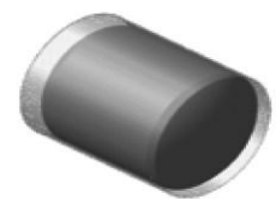

(a)

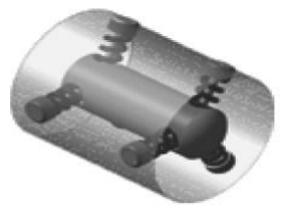

(d)

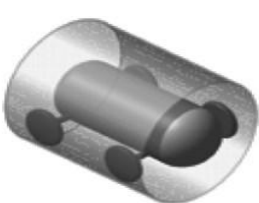

(b)

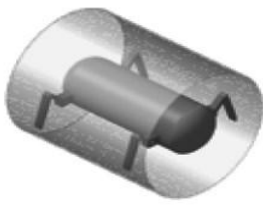

(e)

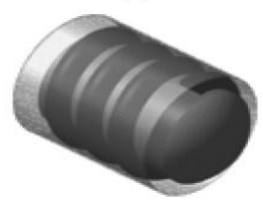

(g)

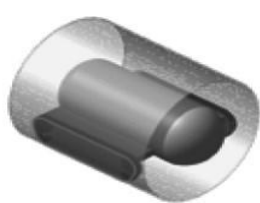

(c)

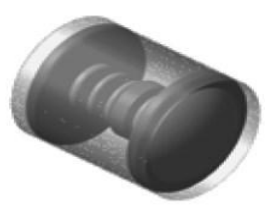

(f)

Fig. 1 Classification of in-pipe robots. (a) Pig type (b) Wheel type (c) Caterpillar type (d) Wall-press type

(e) Walking type (f) Inchworm type (g) Screw type [1] 
The wheel type illustrated in figure 1(b) is similar to the plain mobile robot, and a number of commercialized robots have been reported up to now [3]-[4]. figure 1(c) shows the robot with caterpillars instead of wheels [5]. As shown in figure 1(d), the wall-press type, which has a number of advantages in climbing vertical pipelines, corresponds to the robot with a flexible mechanism for pressing the wall with whatever means they apply [6], [7]. As depicted in figure 1(e), the walking type possessing articulated legs can produce highly sophisticated motions [8]-[9]. The inchworm type given in figure 1(f) is usually employed for pipelines with very small diameters [10]-[11]. The screw type (or helical-drive type) displays the motion of a screw when it advances in the pipelines, as depicted in figure 1(g) [12]-[13]. Almost all in-pipe inspection robots have employed the mechanism derived from one of the above basic types of mechanisms or their combinations.

This paper is organized as follows. Section 2 describes the power sources of pipe inspection robot. Section 3 describes review of in-pipe inspection robot. Section 4 describes the comparative analysis of existing in-pipe inspection robot. Section 5 describes the need of different mechanisms. Section 6 describes development of steering mechanism for improvising working style of in-pipe inspection robot. Section 7 provides summary of all in-pipe inspection robots. Section 8 provides the conclusion and future scope.

\subsection{DC motor}

\section{Power Source Of In-Pipe Inspection Robot}

DC motor is used to control the moving speed of the robot. Also DC motor is used to change the contact angles of the legs and to twist the robot body around 360 degree at a pipe branch.

\subsection{Air pressure system}

The air pressure system is composed of air compressor, solenoid valves and air hoses, as shown in figure 2.
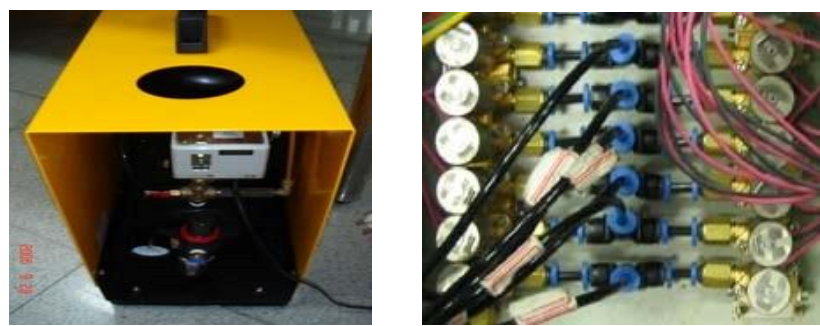

Fig. 2 Air pressure system a) Air compressor, b) Solenoid valves and air hoses [17]

A solenoid valve is an electromechanical valve for use with liquid or gas controlled by running or stopping an electric current. Compressed air that come out from air compressor is supplied to solenoid valve and solenoid valve delivers compressed air to air cylinder of robot.

\subsection{In-pipe Inspection Robot 1}

\section{Review Of In-Pipe Inspection Robots}

Figure 3 shows in-pipe inspection robot which consist of a fore leg system, a rear leg system and a body. The fore and rear leg system are designed as linkage mechanism.

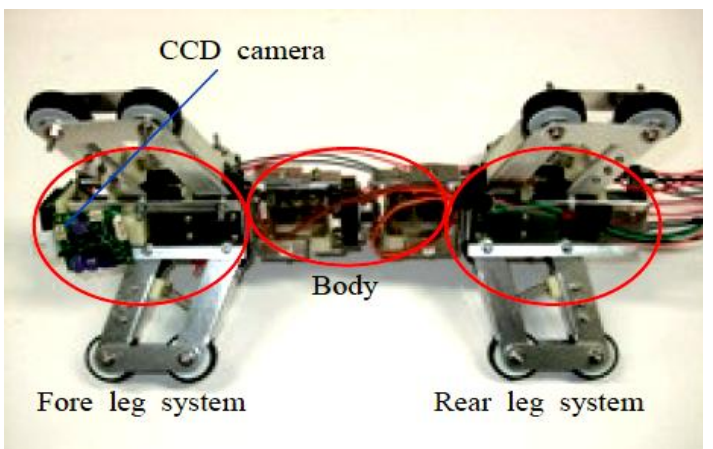

Fig. 3 In-pipe inspection robot [14]

The fore and rear leg system consist of three legs respectively. Each leg has two wheels which is shown in figure 4 (a) \& (b). Three legs of the each leg system have only a DC motor that controls the moving speed of the legs. Moreover, the fore and rear leg system has another motor, respectively to change the contact angle of 
the legs. The fore and rear legs are connected in order to be parallel to each other in their mutual positions. So, it always make the robot's body parallel to the pipe, even though the fore and rear legs are closed.

Three legs of the each leg system are arranged 120 degrees to each other by using worm gear system as shown in figure 4 (b). The worm gear system is constructed by two helical gear sets. The opening or closing angles of the legs are can be kept at same value by using the worm gears. While the legs press against the pipe walls to support the body and they move forward or backward. The front and back part of the robot body have a joint respectively. Each joint has a RC servo motor. Also, a DC motor is installed in the body so that the body can be twisted to around 360 degree at a pipe branch.
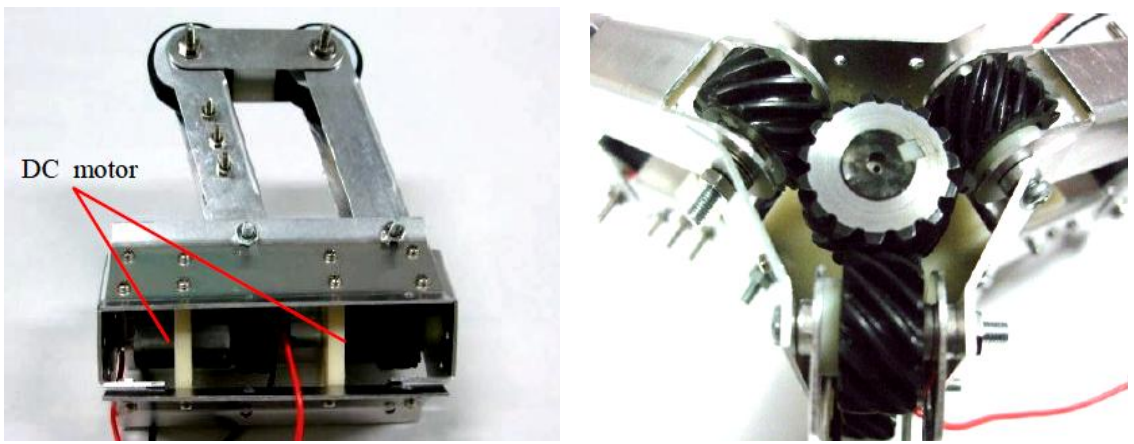

Fig. 4 a) Fore and rear leg system b) Worm gear system [14]

\subsection{MRINSPECT I}

Figure 5 (a) and (b) shows the prototype and the kinematic scheme of the in-pipe inspection robot called MRINSPECT I (Multifunctional Robotic crawler for INpipe inSPECTion). It has six slider-crank mechanisms, arranged at $120^{\circ}$ one from each other, each of these having a driving wheel. The wheels are actuated by DC motors and belt transmission. The robot is designed as the springs to actuate the mechanisms with equal forces. This mechanism allows the robot to move within pipes with horizontal, vertical, and elbowtyped portions. The movement of the robot within $\mathrm{T}$ junctions is not possible.

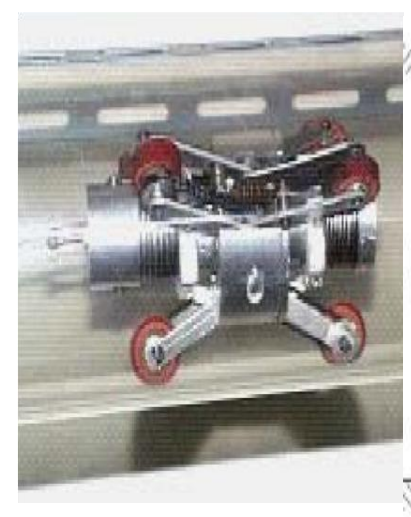

(a)

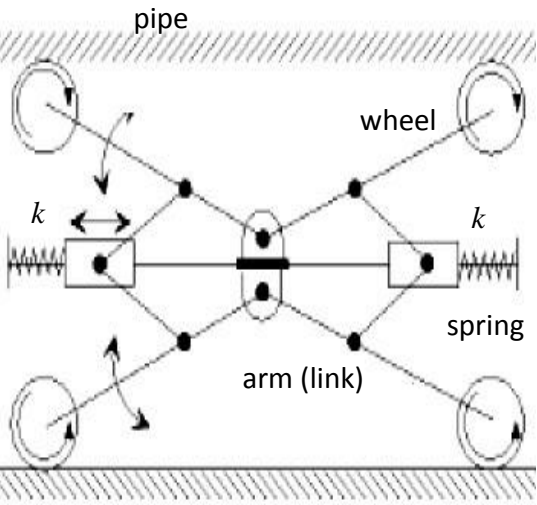

(b)

Fig. 5 (a) MRINSPECT I in-pipe robot (b) its basic mechanism [15]

\subsection{MRINSPECT II}

Figure 6 shows another type of mechanism which can assure the adaptability of robots to different pipe diameters is the modified pantograph, used in the structure of the MRINSPECT II robot. This mechanism allows the movement of the wheels along the radial direction. This aspect is very important, because distortion forces no longer appear, as the robot passes over the obstacles. For the control of the pushing force over the inner surface of the pipe, a linear actuator and two position sensors are used. 


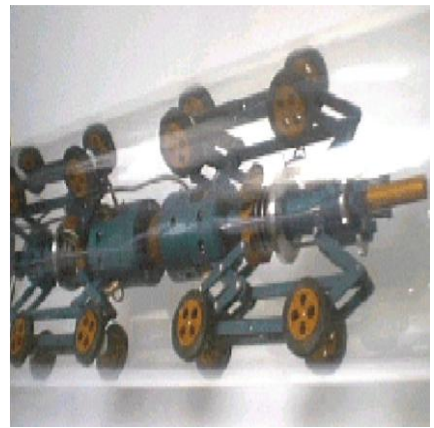

(a)

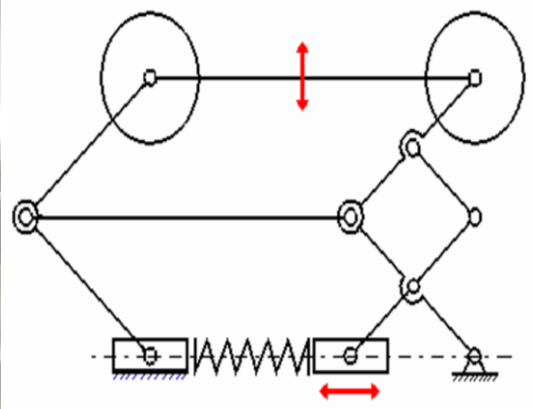

(b)

Fig. 6 (a) MRINSPECT II (b) its mechanism [15]

\subsection{MRINSPECT IV}

Steering mechanism of MRINSPECT IV is shown in figure 7.

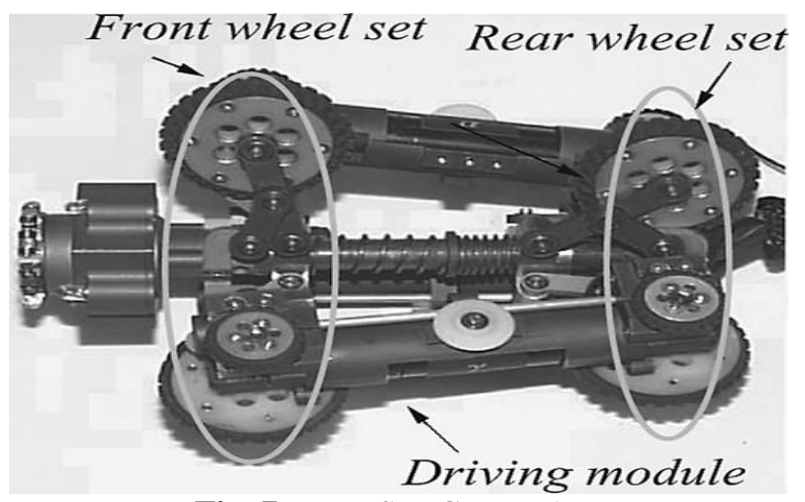

Fig. 7 MRINSPECT IV [16]

MRINSPECT IV composed of a body frame that mounts a CCD camera assembly and driving modules with foldable linkages along with camera assembly which is for the navigation and the visual inspection of the pipelines. Also it consist of three modularized driving modules illustrated in figure 8 which an located circumferentially with $120^{\circ}$ apart.

Figure 8 shows a driving module which consists of a DC motor with an encoder and a reducer, several wheels and casings. The driving units can be controlled independently and thus they amplify the tractive forces as well as provide steering capability.

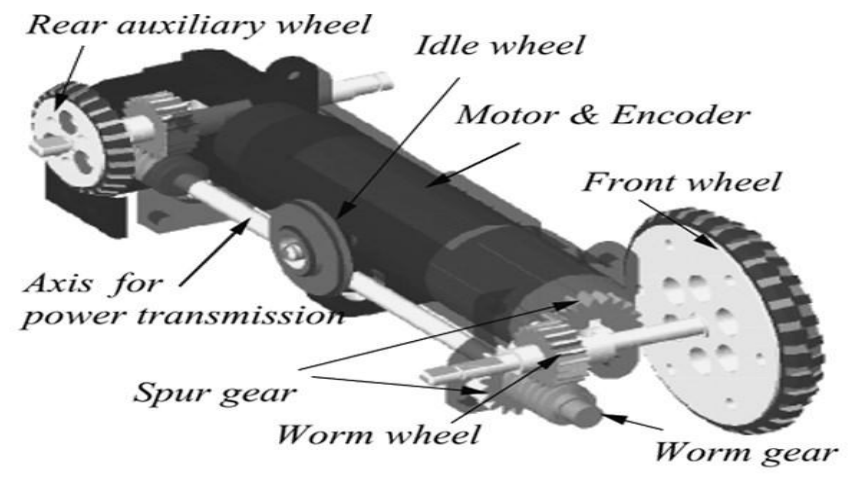

Fig. 8 Driving module [16]

To provide the sufficient tracting forces and flexibility in navigation, a body frame designed which is illustrated in figure 9. At the end of the legs on the body frame three driving modules are fixed $120^{\circ}$ apart circumferentially. 


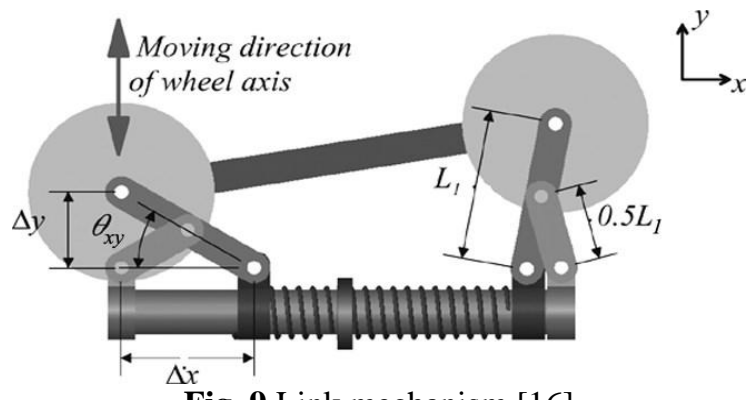

Fig. 9 Link mechanism [16]

Two wheels of the driving module move independently along the radial direction due to constraints of links and interaction between elastic force at the main spring of the body frame and the reaction forces of the wall. Distance between the main shaft of the robot and the wheel changes according to the link construction, and it makes the wheel have effective contact with the wall inside the pipelines whatever diameters changes. It assures stable traveling as long as providing sufficient traction forces. Front wheel of each driving module have been synchronized each other. As shown in figure 7, wheels in front and back of each driving module are named the front wheel set and the back wheel set, respectively. Constraint of the wheels inside each wheel set makes the robot capable of neglecting the effect of gravity, which makes the central axis of the robot always coincide with that of the pipelines.

\subsection{In-Pipe Inspection Robot 2}

In this robot mechanism movement is copied from both the inchworm and the wall press type in nature. For the structure of robot, the proposed mechanism mimicked structure of a folding umbrella as shown in figure 10. The structure of robot is based on 4-bar-link. Size of whole structure can be changed according to change of length of link. Link of the top portion has motion that goes up and down vertically by sliding. Using this, robot gives pressure to pipe and is endured through the friction between the link of the top portion and the pipe.

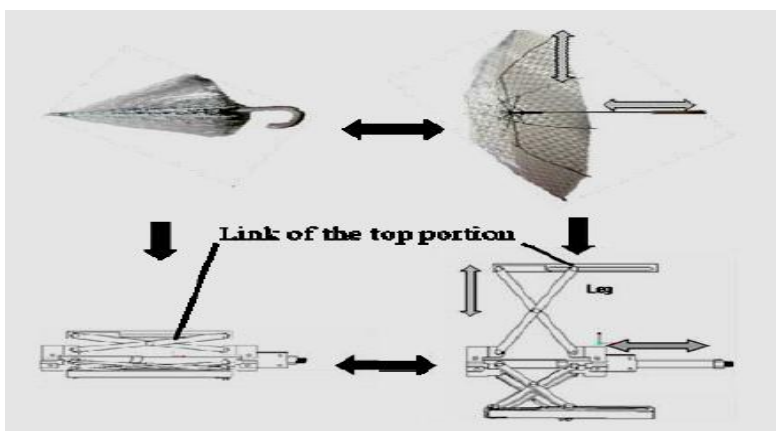

Fig. 10 Clamping device [17]

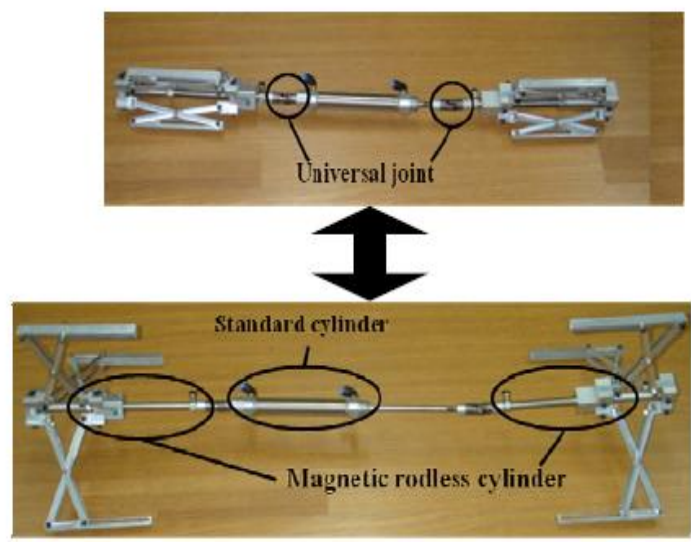

Fig. 11 Mechanism of robot [17]

As figure 11 shows the in-pipe robot is composed of one expansion device, two clamping devices, and two universal joints. The expansion device uses a standard cylinder, while the clamping device uses a magnetic 
rodless cylinder. Using 4-bar-link on front and back side of robot, size of whole structure can be changed according to change of length of link. When pipe was established horizontally or vertically, enough bearing power of robot is required in order to move in pipe.

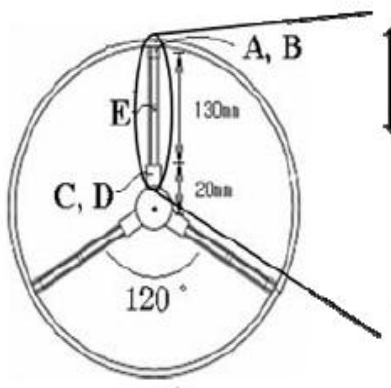

a)

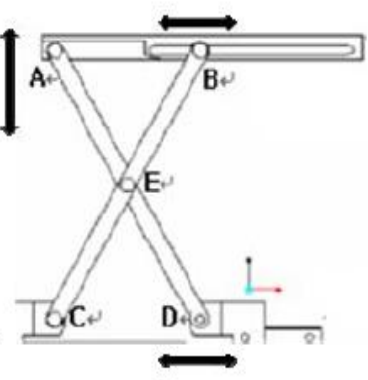

b)

Fig. 12 a) Front view of clamping device b) 4 bar link mechanism [17]

Figure 12 a) shows developed mechanism which is composed of three legs laid apart with 120 degrees and each leg adopts modified expansion mechanism with sliding base and additional four-bar-linkages. The developed mechanism expands along the radial direction. It is a very advantageous feature because the robot can be used with the various Expansive leg mechanism has the motion repeating retraction and extension by sliding action of magnetic-rodless-cylinder in the pipe. If expansive leg mechanism extends, robot hold out by the frictional force between the pipe and supports.

Robot must be able to pass bent pipe to move smoothly in the pipe. Expansive leg mechanism is connected with universal joint to give flexibility to robot. Universal joint is a joint in a rigid rod that allows the rod to 'bend' in any direction, and is commonly used in shafts that transmit rotary motion. It consists of a pair of ordinary hinges located close together, but oriented at $90^{\circ}$ relative to each other.

3.6 LS-01

LS-01 model is as shown in figure 13. LS-01 uses a simple 4-wheeled type robot with foldable top platform acts as the camera holder, called holder for fibre optic camera (HFOC). LS-01 uses a standard differential drive system based on the caterpillar type robot that demand much more grip on the walls of the pipeline. This system allows the robot motion to be controlled smoothly. The rectangular-shape structure is used to house all the components. The robot will enter the boiler header and traverse along the pipe. While moving, the camera captures the view inside the boiler header and transmits the visual through the feed cable to outside viewer.

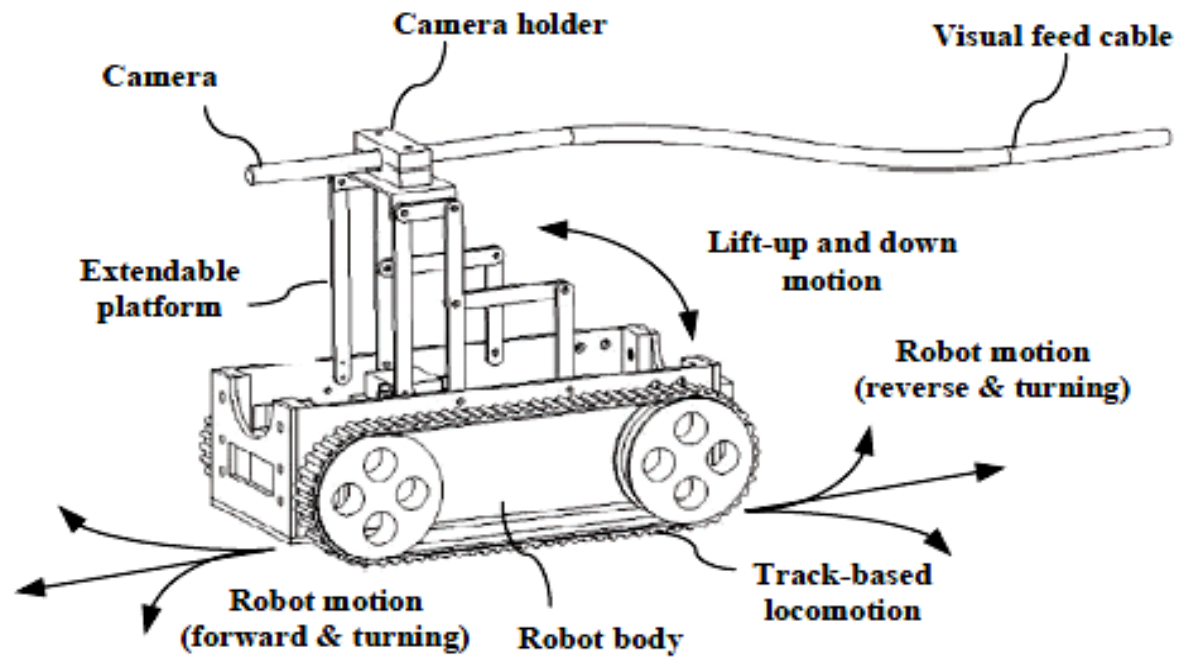

Fig. 13 LS-01 Boiler header inspection robot [18] 


\section{Comparative Analysis Of Existing In-Pipe Inspection Robots}

Table 1 Comparison of Existing IPIR

\begin{tabular}{|c|c|c|c|c|}
\hline Sr. No. & Name of Robot & Author, University \& year & Mechanism & Remark \\
\hline 1. & In-pipe Inspection Robot 1 & $\begin{array}{c}\text { Hun-ok Lim \& Taku Ohki, } \\
\text { Kanagawa, } \\
2009 \\
\end{array}$ & $\begin{array}{l}\text { worm \& worm wheel } \\
\text { mechanism }\end{array}$ & $\begin{array}{l}\text { - Difficult to construct } \\
\text { - More power } \\
\text { consumption }\end{array}$ \\
\hline 2. & MRINSPECT I & $\begin{array}{l}\text { O. Tatar, D. Mandru et al., } \\
\text { Cluj-Napoca, } \\
2007\end{array}$ & $\begin{array}{l}\text { Six slider crank } \\
\text { mechanism }\end{array}$ & $\begin{array}{l}\text { - Movement through T } \\
\text { junction is not possible }\end{array}$ \\
\hline 3. & MRINSPECT II & $\begin{array}{l}\text { O. Tatar, D. Mandru et al., } \\
\text { Cluj-Napoca, } \\
2007 \\
\end{array}$ & Modified pantograph & $\begin{array}{l}\text { - Complex mechanism } \\
\text { - Movement through T } \\
\text { junction is not possible }\end{array}$ \\
\hline 4. & MRINSPECT IV & $\begin{array}{c}\text { Se-gon \& H. R. Choi, } \\
2005\end{array}$ & $\begin{array}{l}\text { slider crank } \\
\text { mechanism }\end{array}$ & $\begin{array}{l}\text { - Complex mechanism } \\
\text { - More power consumption } \\
\text { - High cost }\end{array}$ \\
\hline 5. & In-pipe Inspection Robot 2 & $\begin{array}{c}\text { Yun-Jong Kim, Kyung- } \\
\text { Hyun Yoon et al., } \\
2009\end{array}$ & $\begin{array}{c}\text { Four bar link } \\
\text { mechanism }\end{array}$ & $\begin{array}{l}\text { - Movement through T } \\
\text { junction is not possible } \\
\text { - Compressed air as energy } \\
\text { source }\end{array}$ \\
\hline 6. & LS 01 & $\begin{array}{c}\text { Mohd Zafri Baharuddin, } \\
\text { Juniza Md Saad et al., } \\
\text { Tenaga Nasional Jalan, } \\
2012 \\
\end{array}$ & $\begin{array}{l}\text { Simple 4-wheeled } \\
\text { type } \\
\text { Mechanism }\end{array}$ & $\begin{array}{l}\text { - Movement through only } \\
\text { straight pipes } \\
\text { - Made for only boiler header } \\
\text { inspection }\end{array}$ \\
\hline
\end{tabular}

\section{Need Of Different Mechanisms}

Following are the needs of in-pipe inspection robot:

- Mechanism should be simple

- Power consumption should be low

- Should pass through various pipe elements

- Higher expansion range of legs

- Faster speed

- Accuracy in movement

- Low weight

- User friendly

\section{Developed Steering Mechanism For Improvising Working Style Of In-Pipe Inspection} Robot

Figure 14 and 15 shows the modified steering mechanism of an in-pipe inspection robot. The robot mainly employs aluminium as structural material. This robot composed of body, fore leg system, rear leg system and springs. Fore leg system and rear leg system are symmetric. Each leg system consists of a DC motor, worm gear driving system and three legs. DC motor is prime mover for this robot which is used to drive the robot. Three legs of each leg system are arranged at an angle of 120 degrees to each other to move inside various pipe diameters which is shown in figure 14.

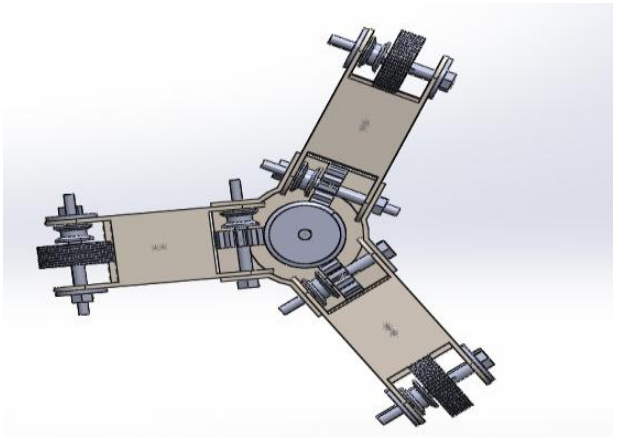

Fig. 14 Fore and rear leg system

Worm gear system is constructed by using a worm and three wheels. Worm is mounted on motor shaft which drives three worm wheels. Each leg consists of a belt drive and two wheels. Belt drive is used to transfer a motion from worm wheel to robot wheel. Coiled spring is attached to each leg and a robot body. By using springs it is able to move freely inside the pipes of $140 \mathrm{~mm}$ to $200 \mathrm{~mm}$ diameter range. 


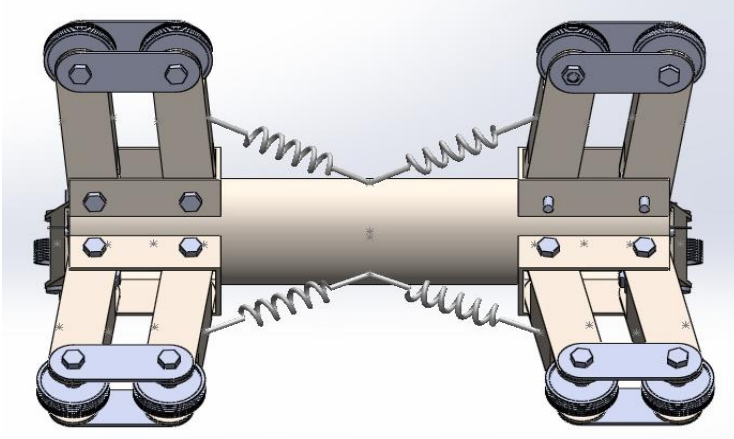

Fig. 15 Assembly of in-pipe inspection robot

Advantages of developed in-pipe inspection robot are as follows:

- Simple steering mechanism which offers robustness and required flexibility.

- Adaptive for various functionality.

- Low cost automation.

- Less power consumption.

- User friendly/simple control system.

\section{Summary}

After doing comparative study of all above robots it is clear that some of the existing robots can freely pass through straight pipes, elbows and $\mathrm{T}$-joints and some of them passes through only straight pipes and elbows. Also, all these robots have complex steering mechanism.

New developed in-pipe inspection robot can freely pass through straight pipes, elbows and reducer of various diameter pipes. Also, its driving mechanism is simple as compared to existing one.

\section{Conclusion}

In this paper construction and steering mechanism of in-pipe inspection robot is discussed. In-pipe inspection robots are mainly differ by steering mechanism, power source, and their application. Existing in-pipe inspection robots are able to move freely inside the straight pipe, elbow and $\mathrm{T}$ joints of different diameter pipes. But driving mechanism of all the pipe inspection robots is complex. So, new and simple driving mechanism of in-pipe inspection robot has been developed. Developed in-pipe inspection robot is able to pass through straight pipelines, elbows and reducer.

In future, driving mechanism of developed robot can be modified to pass through $\mathrm{T}$-joint. Also, by doing the proper configuration of mechanical and electronic parts we can use this developed in-pipe inspection robot for crack detection and visual inspection of various diameter pipelines.

\section{References}

[1] H.R. Choi and S.M Ryew, Robotics system with active steering capability for internal inspection of urban gas pipelines, Mechatronics, vol.26, no.1, 2002, 105-112.

[2] Se-gon Roh and Hyouk Ryeol Choi, Differential-Drive In-Pipe Robot for Moving Inside Urban Gas Pipelines, IEEE TRANSACTIONS ON ROBOTICS, vol. 21, 2005.

[3] T. Okada and T. Kanade, A three-wheeled self-adjusting vehicle in a pipe, FERRET-1, Int. J. Robot. Res., vol. 6, 1987, 60-75.

[4] B. B. Gamble and R. M. Wiesman, Tethered Mouse System for Inspection of Gas Distribution Mains, Gas Res. Inst., Doc. GRI96/0209, 1996

[5] H. T. Roman, B. A. Pellegrino, and W. R. Sigrist, Pipe crawling inspection robots: An overview, IEEE Trans. Energy Convers., vol. 8, 1993, 576-583.

[6] S. M. Ryew, S. H. Baik, S. W. Ryu, K. M. Jung, S. G. Roh, and H. R. Choi, Inpipe inspection robot system with active steering mechanism, in Proc. IEEE Int. Conf. Intelligent Robots, Systems, 2000, 1652-1657.

[7] S. Nagano and Y. Oka, Application of in-pipe visual inspection robot to piping internal surface lining, in Proc. 5th Int. Symp. Robotics in Construction, 1988, 897-906.

[8] W. Neubauer, A spider-like robot that climbs vertically in ducts or pipes, in Proc. IEEE/RSJ Int. Conf. Intelligent Robots, Systems, 1994, 1178-1185.

[9] F. Nickols, D. Ho, S. O. Harrold, R. T. Bradbeer, and L. Yeung, An ultrasonically controlled robot submarine for pipe inspection, in Proc. 4th Annu. Conf. Mechatronics, Machine Vision in Practice, 1997, 142-147.

[10] T. Fukuda, H. Hosokai, and M. Uemura, Rubber gas actuator driven by hydrogen storage alloy for in-pipe inspection mobile robot with flexible structure, in Proc. IEEE Int. Conf. Robotics, Automation, vol. 3, 1989, 1847-1852.

[11] C. Anthierens, A. Ciftci, and M. Betemps, Design of an electro pneumatic micro robot for in-pipe inspection, in Proc. IEEE Int. Symp. Industrial Electronics, vol. 2, 1999, 968-972.

[12] I. Hayashi and N. Iwatsuki, Micro moving robotics, in Proc. IEEE Int. Conf. Intelligent Robots, Systems, 1998, 41-50.

[13] S. Iwashina, I. Hayashi, N. Iwatsuki, and K. Nakamura, Development of in-pipe operation micro robots, in Proc. Int. Symp. Micro Machines, Human Science, 1994, 41-45. 
[14] Yun-Jong Kim, Kyung-Hyun Yoon and Young-Woo Park, Development of the Inpipe Robot for Various Sizes, IEEE International Conference on Advanced Intelligent Mechatronics Suntec Convention and Exhibition Center, 2009.

[15] Hun-ok Lim and Taku Ohki, Development Of Pipe Inspection Robot, ICROS-SICE International Joint Conference, 2009.

[16] S. G. Roh, S. M. Ryew, J. H. Yang and H. R Choi, Actively Steerable Inpipe Inspection Robots for Underground Urban Gas Pipelines, IEEE International Conference on Robotics \& Automation, 2001.

[17] Mohd Zafri Baharuddin, Juniza Md Saad et al., Robot For Boiler Header Inspection “LS 01, ” International Symposium on Robotics and Intelligent Sensors, 2012.

[18] J. Okamoto, Jr., J. C. Adamowski, M. S. G. Tsuzuki, F. Buiochi, and C. S. Camerini, Autonomous system for oil pipelines inspection, Mechatronics, vol. 9, 1999, 731-743.

[19] O. Tatar, D. Mandru and I. Ardelean, Development of mobile minirobots for in pipe inspection tasks, MECHANIKA, 2007. 